\title{
natureouTLOOK MEDICAL RESEARCH MASTERCLASS
}

16 October 2014 / Vol 514 / Issue No 7522

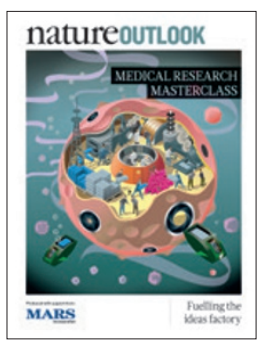

Cover art: Nils-Petter Ekwall

Editorial

Herb Brody,

Michelle Grayson,

Matthew Chalmers,

Kathryn Miller

Art \& Design

Wesley Fernandes,

Mohamed Ashour,

Alisdair Macdonald,

Andrea Duffy

Production

Karl Smart,

lan Pope,

Robert Sullivan

Sponsorship

Reya Silao,

Yvette Smith

Marketing

Hannah Phipps

Project Manager

Anastasia Panoutsou

Art Director

Kelly Buckheit Krause

Publisher

Richard Hughes

Chief Magazine Editor

Rosie Mestel

Editor-in-Chief

Philip Campbell
$\mathrm{I}$ $\mathrm{t}$ is no exaggeration to say that the annual Lindau Nobel Laureate Meetings can be a life-changing experience for many of the 600 or so young scientists who attend. Researchers, all aged under 35, are selected from thousands of applicants from more than 80 countries and, this year, some were lost for words when asked to sum up the experience of what it meant to spend a week mingling with their scientific heroes on the German island of Lindau.

After all, where else can you rub shoulders with the discoverer of HIV, the person who uncovered the genetic foundations of cancer, or the scientist who risked his life to prove that stomach ulcers are caused by a bacterium?

This year's Lindau meeting, the 64th held since 1951, was themed physiology or medicine and took place between 29 June and 4 July, with 37 laureates in attendance. For the first time, there were more female young researchers than male.

Some laureates were familiar faces, such as Werner Arber, for whom it was his 26 th visit. Others, including Michael Bishop, Jules Hoffmann and Barry Marshall, were new to the experience. Despite a busy schedule, the laureates clearly enjoyed exchanging ideas with the next generation.

Taking inspiration from the opening lecture by Randy Schekman, who shared the 2013 Nobel prize for work on the cell's internal transport systems, we report on the part played by autophagy in conditions such as cancer and Alzheimer's disease (page S2). There are discussions - initiated by Nature Video and available at www.nature.com/lindau/2014 - between young researchers and laureates on the science and ethics of ageing (S14) as well as Q\&As with six laureates, conducted and written by young scientists (S5).

We are pleased to acknowledge the financial support from Mars, Incorporated in producing this Outlook. As always, Nature has sole responsibility for all editorial content.

\section{Matthew Chalmers \\ Contributing Editor}

Nature Outlooks are sponsored supplements that aim to stimulate interest and debate around a subject of interest to the sponsor, while satisfying the editorial values of Nature and our readers' expectations. The boundaries of sponsor involvement are clearly delineated in the Nature Outlook Editorial guidelines available at go.nature.com/e4dwzw

CITING THE OUTLOOK

Cite as a supplement to Nature, for example, Nature Vol. XXX, No. XXXX Suppl., Sxx-Sxx (2014).

VISIT THE OUTLOOK ONLINE

The Nature Outlook Medical Research Masterclass supplement can be found at http://www.nature.com/nature/outlook/masterclass 2014

It features all newly commissioned content as well as a selection of

relevant previously published material.
All featured articles will be freely available for 6 months. SUBSCRIPTIONS AND CUSTOMER SERVICES For UK/Europe (excluding Japan): Nature Publishing Group, Subscriptions, Brunel Road, Basingstoke, Hants, RG21 6XS, UK Tel: +44 (0) 1256329242 . Subscriptions and customer services for Americas - including Canada, Latin America and the Caribbean: Nature Publishing Group, 75 Varick St, 9th floor, New York, NY 10013-1917, USA. Tel: +1 8663637860 (US/Canada) or +1 212726 9223 (outside US/Canada). Japan/China/Korea: Nature Publishing Group - Asia-Pacific, Chiyoda Building 5-6th Floor, 2-37 Ichigaya Tamachi, Shinjuku-ku, Tokyo, 162-0843, Japan. Tel: +81 332678751. CUSTOMER SERVICES

Feedback@nature.com

Copyright $\odot 2014$ Nature Publishing Group

\section{CONTENTS}

S2 MOLECULAR BIOLOGY

Remove, reuse, recycle

We talk to experts in the rapidly

evolving field of cell autophagy

S5 Q\&A

Fighting fit: Jules Hoffmann

S6 Q\&A

A bold experiment: Barry Marshall

S8 Q\&A

HIV adversary: Françoise

Barré-Sinoussi

S9 Q\&A

Free thinker: Michael Bishop

S11 Q\&A

Progress in sight: Torsten Wiesel

S12 Q\&A

Stuck on structure: Brian Kobilka

S14 GERONTOLOGY

Will you still need me, will you still feed me?

Nobel laureates and young researchers discuss the science behind the ageing process, in a session with Nature Video

\section{COLLECTION}

S16 Eaten alive: a history of macroautophagy Zhifen Yang \& Daniel J. Klionsky

\$25 Stop the microbial chatter Vivien Marx

S29 An intergovernmental panel on antimicrobial resistance Mark Woolhouse \& Jeremy Farrar

S32 My life with Parkinson's Anonymous

S34 Fifty years of EMBO Georgina Ferry

\$36 Turning brain drain into brain circulation Torsten Wiesel

S38 NIH plans to enhance reproducibility Francis S. Collins \& Lawrence A. Tabak

S40 More than a crystallographer Laura Cassiday

S43 Cancer killers Rachel Bernstein

\$45 Biomedical burnout Warren Hollemann \& Ellen R. Gritz 